\title{
Budaya Pluralisme dalam Penerimaan Masyarakat Desa Balun, Kabupaten Lamongan
}

\section{Pluralism Culture in Community Reception Balun Village, Lamongan Regency}

\author{
Fatkhur Rozi ${ }^{1 *}$, Djarot Meidi Budi Utomo ${ }^{2}$ \\ ${ }^{1}$ IImu Komunikasi, Universitas Muhammadiyah Sidoarjo, ${ }^{2}$ IImu Komunikasi, Universitas Muhammadiyah Sidoarjo
}

Balun Village is an interesting village to this study. The village, called the Pancasila Village, has always instilled the values of pluralism in daily life and well-preserved until today. Now, Pluralism has changed shape into a culture. The SARA issues that still exist in Indonesia. There are no ways to give a significant impact and influence in Balun village people's acceptance of the culture of pluralism. The phenomenological approach with indepth interviews is used to find out the accepted (reception) of the community towards the culture of pluralism. From the results of the study, it can be seen that Balun village community acceptance of pluralism culture is very good. This acceptance is inseparable from the existence of family ties among Balun village communities. But, their perceptions are still based on reason, which can be seen in their perceptions that see pluralism as a virtue and has a lot of benefits to create a harmonious and peaceful in social life.

Keywords: Phenomenology, Reception, Pluralism

OPEN ACCESS ISSN 2541-2841 (online) ISSN 2302-6790 (print)

Edited by: Ainur Rochmaniah

Reviewed by: Najib Husain

${ }^{*}$ Correspondence: Fatkhur Rozi

fatkhurrozi024@umsida.ac.id

Received: 2 Juli 2019

Accepted: 4 Juli 2019

Published: 1 September 2019

Citation:

Rozi F and Utomo DMB (2019)

Budaya Pluralisme dalam Penerimaan Masyarakat Desa

Balun, Kabupaten Lamongan. Kanal. 8:1.
Desa Balun merupakan salah satu desa yang menarik untuk diteliti. Desa yang berjuluk Desa Pancasila ini senantiasa menanamkan nilai-nilai pluralisme dalam kehidupan seharihari dan terjaga dengan baik hingga saat ini. Pluralisme tersebut kini telah berubah bentuk menjadi sebuah budaya. Isu-isu SARA yang masih eksis di Indonesia, sama sekali tidak memberikan dampak dan pengaruh yang berarti dalam penerimaan masyarakat desa Balun terhadap budaya pluralisme tersebut. Pendekatan fenomenologi dengan wawancara mendalam digunakan untuk mengetahui penerimaan (resepsi) masyarakat terhadap budaya pluralisme tersebut. Dari hasil penelitian, dapat diketahui bahwa penerimaan masyarakat desa Balun terhadap budaya pluralisme terjadi dengan sangat baik. Penerimaan tersebut memang tidak terlepas dari adanya ikatan keluarga antar sesama masyarakat desa Balun. Tetapi persepsi mereka tetap berlandaskan oleh akal budi, yang dapat dilihat pada persepsi mereka yang memandang pluralisme sebagai suatu kebaikan dan mempunyai manfaat yang begitu besar guna menciptakan kehidupan bermasyarakat yang rukun dan damai.

Keywords: Fenomenologi, Resepsi, Pluralisme 


\section{PENDAHULUAN}

Indonesia di kenal sebagai salah satu negara yang majemuk. Terdapat 6 agama besar dan lebih dari 1.300 suku yang mendiami Indonesia [1] Statisik (2010). Ironisnya, konflik berlatar belakang suku, agama,ras, antar golongan (SARA) masih saja terjadi di negara berslogan Bhinneka Tunggal Ika ini. Kondisi Indonesia yang majemuk memang sangat rentan dan berpotensi untuk menciptakan kesalahpahaman dan prasangka negatif, dimana hal tersebut merupakan pemicu utama terjadinya konflik [2] BLDDKARI (2008). Hidup di bawah payung kemajemukan, memang sangat membutuhkan adanya toleransi dalam kehidupan sehari-hari,tidak lain adalah demi tercipta kehidupan yang damai.

Toleransi merupakan salah satu nilai dalampluralisme. Pluralisme sendiri bukanlah suatu hal yang baru di Indonesia, mengingat slogan "Bhinneka Tunggal Ika " yang terdapat pada lambang negara Republik Indonesia tersebut merupakan s imbol pluralisme yang dibangun oleh Hindu dan Buddha jauh sebelum Negara Kesatuan Republik Indonesia berdiri [3] Kuswanjono (2006). Lengkapnya,sloka tersebut berbunyi Bhinneka Tunggal Ika, Tan Hana Dharma Mangrua, yang mempunyai arti bahwa beragam dalam kesatuan, tidak ada "dharma" yang mendua.Menurut Kamus Besar Bahasa Indonesia (KBBI) [4] Indonesia (2008), pluralisme merupakan suatu keadaan masyarakat yang majemuk (mengenai agama, budaya, sosial, maupun politik). Terdapat pendapat lain yang mengatakan bahwa pluralisme adalah sebuah seni untuk menghargai segala perbedaan tetapi tetap memegang teguh prinsip yang dimiliki [5] Sumbullah (2013). Lebih jauh lagi, pluralisme mengisyaratkan tentang adanya keharusan individu untuk benar-benar terlibat dalam kenyataan akan kemajemukan yang ada [6] Shihab (1999). Singkatnya, pluralisme merupakan paham yang mengakui adanya kemajemukan (baik dalam aspek agama, budaya, sosial, dan politik). T idak hanya sekedar mengakui, individu diharuskan untuk ikut berkontribusi secara aktif dalam kemajemukan yang ada.

Ditengah hangatnya isu SARA yang terus beredar di Indonesia, terdapat sebuah desa di Kabupaten Lamongan yang senantiasa hidup rukun dan damai, meskipun desa tersebut dipayungi oleh perbedaan agama selama berpuluh-puluh tahun. Desa tersebut bernama Balun, termasuk ke dalam wilayah Kabupaten Lamongan.Kondisi sosialyang sedemikian rupa,membuatnya dijuluki sebagai Desa Pancasila oleh masyarakat luas. Agama yang terdapat di desa Balun meliputi Islam, Kristen, dan Hindu.

Julukan Desa Pancasila tersebut sudah tersemat selama 10 tahun. Berawal ketika desa Balun semakin ramai dan sering dikunjungi oleh para mahasiswa, peneliti, FKUB, dll. hingga kemudian muncullah julukan Desa Pancasila yang berasal dari ungkapan mereka yang tengah atau telah selesai mengunjungi desa Balun. Ketika mengunjungi desa Balun, mata kita memang akan langsung disuguhi dengan adanya bangungan rumah ibadah yang letaknya sangat berdekatan. Bangunan-bangunan megah masjid, gereja, dan pura seolah menjadi representati $\mathrm{f}$ dari kehidupan sosial masyarakat desa Balun.

Terkait budaya pluralisme yang terdapat di desa Balun, berawal ketika pak Bati terpilih dan mulai menjabat sebagai Kepala Desa pada tahun 1966. Bap ak Bati merupakan tokoh kunci dalam lahirnya pluralisme di desa Balun, yang bisa dibuktikan dengan adanya agama Kristen dan Hindu yangmasuk dan berkembang sejak tahun 1967. Hingga saat ini, k edua agama tersebut mampu untuk hidup berdampingan secara harmonis dengan agama Islam yang memang menjadi agama asli masyarakat desa Balun. Pluralisme yang telah tercipta dan diwariskan dari generasi ke generasi tersebut, kini telah berubah bentuk menjadi budaya yang terus dilestarikan oleh generasi penerus desa Balun.

Dari uraian di atas, maka penerimaan atau resepsi masyarakat desa Balun terhadap budaya pluralisme tersebut sangat menarik untuk ditetili. Mengingat kondisi Indonesia yang hingga kini masih diselimuti oleh berbagai isu SARA, sama sekali tidak memberikan dampak dan pengaruhnya dalam penerimaan masyarakat desa Balun terhadap budaya pluralisme tersebut. Resepsi merupakan tindakan penerimaan oleh masyarakat yang syarat akan latar belakang sosial, budaya, dan pendidikan. Penerimaan masyarakat tersebut meliputi aspek persepsi, keinginan (preferensi), sikap, dan perilaku [7] Rochmaniah et al. (2015). Penelitian ini dilakukan untuk melihat bagaimana penerimaan masyarakat desa Balun terhadap budaya pluralismeyang tetap lestari hingga saat ini dengan menggunakan pendekatan 


\section{METODE PENELITIAN}

Dalam upaya untuk mengetahui bagaimana penerimaan masyarakat desa Balun terhadap penerimaan budaya pluralisme, peneliti menggunakan pendekatan fenomenologi dalam penelitian kualitatif ini.Lokasi penelitian ini yaitu di desa Balun, Kecamatan Turi, Kabupaten Lamongan. Subyek dalam penelitian ini adalah masyarakat desa Balun, sedangkan yang menjadi obyeknya adalah pluralisme itu sendiri. Teknik pengumpulan data yang digunakan berupa wawancara mendalam, observasi, dan dokumentasi. Wawancara mendalam dilakukan terhadap 10 orang informan. Data yang diperoleh kemudian diolah dengan menggunakan teknik analisis yang biasanya digunakan dalam penelitian fenomenologi, diantaranya adalah :

1. Tahap awal, berupa pendeskripsian secara penuh fenomena yang dialami oleh subyek, kemudian mentranskripkan seluruh hasil wawancara.Horisonalisasi, dari hasil transkripsi tersebut dipilih sesuai dengan pertanyaan yang terdapat di pedoman wawancara.

2. Horisonalisasi, dari hasil transkripsi tersebut dipilih sesuai dengan pertanyaan yang terdapat di pedoman wawancara.

3. Cluster of meaning, hasil dari transkrip yang sudah dipilah kemudian digolongkan atau disortir ke dalam unit makna atau kategori.

4. Tahap selanjutnya adalah deskripsi esensi yang didalamnya peneliti mendeskripsikan secara menyeluruh terhadap makna dan esensi pengalaman dari para subyek.

5. Terakhir, peneliti membuat kesimpulan dan laporan.[8] Hasbiansyah (2008)

\section{HASIL DAN PEMBAHASAN}

Konsep penerimaan yang digunakan dalam penelitian ini adalah resepsi atau penerimaan masyarakat oleh Rochmaniah et al dimana resepsi merupakan tindakan penerimaan oleh masyarakat yang syarat akan latar belakang sosial, budaya, dan pendidikan. Penerimaan masyarakat tersebut meliputi aspek persepsi, keinginan (preferensi), sikap, dan perilaku [7] Rochmaniah et al. (2015). Sederhananya, penerimaan masyarakat merupakan suatu proses pemaknaan mengenai sebuah obyek dan akan menghasilkan sebuah respon atau reaksi atas obyek tersebut. Uraiannya adalah sebagai berikut :

\section{Persepsi}

Berpegang pada konsep penerimaan masyarakat Rochmaniah et al yang mengatakan bahwa resepsi merupakan tindakan penerimaan oleh masyarakat yang syarat akan latar belakang sosial, budaya, dan pendidikan. Penerimaan masyarakat tersebut meliputi aspek persepsi, keinginan (preferensi), sikap, dan perilaku [7] Rochmaniah et al. (2015). Maka yang pertama kali dibahas adalah aspek persepsi.

Persepsi merupakan upaya dalam memperoleh kesadaran terhadap lingkungan sekitarnya [9] Mulyana (2010). Persepsi berkaitan erat dengan upaya-upaya untuk mendapatkan pengetahuan khusus mengenai fenomena, sekaligus berkenaan dengan sisi kognitif atau pengetahuan. Dengan kata lain, persepsi berisi penafsiran mengenai obyek atau tanda-tanda berdasarkan sudut pandang seorang individu, dimana hal tersebut berpengaruh terhadap perilaku dan pembentukan sikap [10] Walgito (2001).

Berdasarkan hasil wawancara mendalam diketahui bahwa masyarakat desa Balun memandang pluralisme sebagai sebuah kebaikan dan memberikan banyak sekali manfaat positif, khususnya kerukunan dalam kehidupan bermasyarakat sehari-hari. Selain itu, masyarakat desa Balun juga memandang pluralisme sebagai suatu keindahan. Dianalogikan seperti bunga di taman yang akan terlihat indah apabila terdiri dari berbagai macam warna. Dari analogi tersebut dapat ditarik sebuah makna, bahwa antara satu sama lain yang pada dasarnya memang berbeda sedari awal sudah seharusnya bersatu untuk mencapai persatuan. Kemudian p ersatuan tersebut akan menimbulkan adanya sebuah keindahan. 


\section{Keinginan ( $\mathrm{P}$ referensi)}

Aspek k edua adalah mengenai keinginan atau preferensi. Menurut Kamus Besar Bahasa Indonesia (KBBI) [4] Indonesia (2008), preferensi merupakan kecenderungan untuk memilih atau memprioritaskansalah satu daripada yang lainnya. Terdapat pendapat lain yang menyatakan bahwa preferensi merupakan salah satu unsur atau komponen yang mempengaruhi individu dalam membuat sebuah keputusan [11] Saputra (2000). Pada dasarnya, individu memang memiliki keinginan atau preferensi tersendiri dalam membuat atau menentukan pilihannya.

Dalam penelitian ini, peneliti ingin melihat pilihan atau kecenderungan yang melatar belakangi penerimaan masyarakat desa Balun dalam menerima bud a ya pluralisme. Dimana keinginan tersebut dipengaruhi langsung oleh adanya kecenderungan yang muncul setelah individu memiliki persepsi terhadap suatu obyek atau tanda.

Berdasarkan hasil wawancara mendalam, dapat diketahui bahwa yang melatar belakangi keinginan atau preferensi masyarakat desa Balun dalam menerima budaya pluralisme yang telah diwariskan secara turun temurun adalah adanya rasa persaudaraan yang erat antar tiga komunitas agama tersebut. Hal itu dikarenakan masih adanya ikatan keluarga diantara mereka. Ketika ditarik sebuah garis, maka mayoritas masyarakat desa Balun memiliki ikatan keluarga, meskipun hanya sebatas saudara ipar atau saudara jauh. Dalam satu Kartu Keluarga misalnya, sebagian besar terdiri dari dua agama yang berbeda. Selain itu, terdapat hal lain, yaitu rasa tanggung jawab sebagai generasi penerus yang bekrwajiban untuk melestarikan budaya pluralisme yang telah terpelihara selama berpuluh-puluh tahun tersebut.

\section{Sikap}

Aspek ketiga adalah sikap. Menurut Kamus Besar Bahasa Indonesia (KBBI) [4] Indonesia (2008), sikap merupakan perbuatan yang berlandaskan pada pendirian atau keyakinan individu. Pendapat lain menyatakan bahwa s ikap merupakan sebuah keteraturan tertentu terhadapperasaan (afeksi),pemikiran (kognisi ), dantindakan (konasi) seseorang mengenai sesuatu yang ada di lingkungan sekitarnya [12] Azwar (2013). Sederhananya, sikap merupakan perbuatan atau cara bertindak baik positif ataupun negatif terhadap suatu obyek yang ada di lingkungan sekitarnya.

Terdapat banyak sekali faktor yang mempengaruhi sikap individu terhadap suatu obyek, diantaranya adalah pengalaman pribadi, pengaruh orang lain yang dianggap penting, pengaruh kebudayaan, media massa, lembaga p endidikan, dan faktor emosional [12] Azwar (2013).

Berdasarkan hasil wawancara mendalam dapat diketahui bahwa masyarakat desa Balun setuju dengan adanya budaya pluralisme tersebut. Hal itu dapa t dibuktikan dengansetiap masyarakat desa Balun turut berkontribusi dalam pelestarian budaya pluralisme. Para orang tua senantiasa menjadi perpanjangan tangan dari pak Bati dengan meneruskan budaya tersebut kepada generasi-generasi selanjutnya. Hal itu dilakukan dengan ca ra mendidik dan senantiasa memberikan pemahaman, pandangan, dan nasihat-nasihat yang berpegang pada nilai-nilai pluralisme.

\section{Perilaku}

Aspek terakhir adalah perilaku. Menurut Kamus Besar Bahasa Indonesia (KBBI) [4] Indonesia (2008), perilaku merupakan reaksi atau tanggapan individu terhadap lingkungan sekitarnya. Terdapat adanya pendapat lain yang mengatakan bahwa perilaku merupakan semua hal yang berakar pada aktivitas individu itu sendiri, terutama yang menimbulkan adanya reaksi [13] Notoadmodjo (2007). Maka, stimulus tertentu akan menghasilkan perilaku tertentu juga, serta diikuti dengan adanya pandangan dan kecenderungan untuk bertindak dengan mengacu sesuai dengan obyek.

Aspek terakhi r yang berupa perilaku, merupakan manifestasi dari ketiga aspek sebelumnya, yaitu persepsi, keinginan (preferensi), dan sikap. Penerimaan budaya puralisme oleh masyarakat desa Balun tentu linier dengan perilaku dalam kehidupan bermasyarakatnya. Hal itu terwujud dengan begitu beranekaragam nya bentuk-bentuk pluralisme yang ada di desa 
Balun. Contohnya,pada saat hari besar masing-masing agama, anggota dari komunitas lain yang tidak merayakan akan menjaga dan mengamankan jalannya ibadah yang tengah berlangsung. Hal itu tanpa diawali dengan adanya sebuah permintaan terlebih dahulu, semua murni inisiatif diri sendiri. Meskipun pihak Polsek dan TNI AD setempat sudah melakukan penjagaan, mereka tetap senantiasa melakukan pengamanan demi lancarnya ibadah yang tengah berlangsung. Selain itu, ketika terdapat masyarakat desa Balun yang meninggal, seluruh masyarakat akan turut membantu. Semua yang hadir membantu akan terlihat seragam, dengan berpakaian rapi, bersarung, dan berpeci. Tetapi mereka sebenarnya berasal dari tiga agama yang berbeda. Dalam proses penguburan nya juga dibebaskan siapa saja untuk membantu, kecuali ketika proses dari ritual agama masing-masing, hanya yang agamanya sama yang mengikuti semacam ritual menyucikan mayat sebelum dikubur. Hal lainnya berupa ketika menjalani ritual agama masing-masing pada setiap harinya, akan terlihat penerimaan terhadap budaya pluralisme memang sangat baik. Pada saat pura tengah melakukan ritual Tumpak Landep (Odalan), maka masjid hanya melakukan azan dan iqomah, serta hanya dimasukkan ke speaker yang ada di dalam masjid. Begitupun ketika memasuki waktu sholat, suara gamelan yang dimasukkan ke dalam soundsystem akan segera dikecilkan. Tradisi ngaturi atau dalam bahasa Indonesia berarti mengundang untuk mengh a diri hajatan atau syukuran juga me rupakan bentuk pluralisme pada masyarakat desa Balun. Undangan tersebut tidak hanya disampaikan kepada yang agamanya sama, tetapi juga pada yang berlainan agama. Meskipun demikian, yang berbeda agama tersebut tetap khusyuk dalam mengikuti serangkaian acaranya. Tetapi ketika memasuki sesi do ' a, mereka yang berbeda agama $\mathrm{m}$ em a ng berdoa sesuai dengan agama masing-masing.

\section{KESIMPULAN}

Pluralisme yang tercipta sejak berpuluh-puluh tahun lamanya dan tetap lestari hingga kini, serta telah membudaya di lingkungan desa Balun, memang tidak bisa dilepaskan dari adanya penerimaan oleh masyarakat nya. Dari hasil wawancara mendalam, dapat diketahui bahwa $\mathrm{p}$ enerimaan masyarakat terhadap budaya pluralisme ter jadi dengan sangat baik, sehingga penerimaan tersebut tidak ter pengaruh oleh keadaan di Indonesia yang hingga kini masih be rada di bawah bayang-bayang berbagai isu SARA.

Penerimaan tersebut memang tidak terlepas dari adanya ikatan keluarga antar sesama masyarakat desa Balun. Tetapi persepsi mereka tetap berlandaskan oleh akal budi, yang dapat dilihat pada persepsi mereka yang memandang pluralisme sebagai suatu kebaikan dan mempunyai manfaat yang begitu besar guna menciptakan kehidupan bermasyarakat yang rukun dan damai.

\section{REFERENCES}

Azwar, S. (2013). Sikap Manusia Teori dan Pengukurannya (Yogyakarta: Pustaka Pelajar).

BLDDKARI (2008). Merajut Kerukunan Umat Beragama Melalui Dialog Pengembangan Wawasan Multi Kultural (Departemen Agama RI).

Hasbiansyah, O. (2008). Pendekatan Fenomenologi: Pengantar Praktik Penelitian dalam Ilmu Sosial dan Komunikasi. Mediator: Jurnal Studi Agama-Agama 9, 163-180.

Indonesia, D. P. (2008). Kamus Besar Bahasa Indonesia (Jakarta: Balai Pustaka).

Kuswanjono, A. (2006). Pluralisme Pancasila. Jurnal Filsafat 39, 77-93.

Mulyana, D. (2010). Ilmu Komunikasi: Suatu Pengantar (Bandung: Remaja Rosda Karya).

Notoadmodjo, S. (2007). Ilmu Perilaku (Jakarta: Rineke Cipta).

Rochmaniah, A., Abadi, T. W., and Fitria, I. (2015). Society Reception on the Marine Ecotourism in Minneapolitan Region of Sidoarjo District. Asian Journal of Humanities and Social Studies 3, 433-439.

Saputra, I. (2000). Preferensi Masyarakat Terhadap Hutan Kota.
Shihab, A. (1999). Islam Inklusif Menuju Sikap terbuka dalam Beragama (Jakarta: Mizan).

Statisik, B. P. (2010). BPS Kewarganegaraan Sukubangsa Agama Bahasa 2010 (Jakarta: Badan Pusat Statisik).

Sumbullah, U. N. (2013). Makna dan Lokalitas Pola Kerukunan Antarumat Beragama (Malang: UIN-Maliki Press).

Walgito, B. (2001). Psikologi Sosial: Suatu Pengantar (Yogyakarta: Andi Offset).

Conflict of Interest Statement: The authors declare that the research was conducted in the absence of any commercial or financial relationships that could be construed as a potential conflict of interest.

Copyright (c) 2019 Rozi and Utomo. This is an open-access article distributed under the terms of the Creative Commons Attribution License (CC BY). The use, distribution or reproduction in other forums is permitted, provided the original author(s) and the copyright owner(s) are credited and that the original publication in this journal is cited, in accordance with accepted academic practice. No use, distribution or reproduction is permitted which does not comply with these terms. 